\title{
Climate and cultural barriers to northern economic development: a case study from Broughton Island, N.W.T., Canada
}

\author{
Jill Oakes \\ Department of Native Studies, and Natural Resource Institute, University of Manitoba, Winnipeg, Manitoba, Canada R3T 2N2 \\ and \\ Canadian Circumpolar Institute, University of Alberta, Edmonton, Alberta, Canada T6G 2J6
}

\begin{abstract}
It is critical to study climate and cultural factors influencing the handicraft industry in order to combat critical levels of unemployment in northern settlements. The purpose of this paper is to identify the climate and cultural factors influencing production at the Minnguq Sewing Group in Broughton Island, Northwest Territories, Canada. Participatory action research methods, including participation in workshops, observing the decision making processes, and informal interviews were used during the field research conducted from January to August 1991. Information was collected on various aspects of business including product line development, production techniques, management strategies, and funding sources. Climate and culture influenced availability of resources, funding, and training; isolation from consumers and supplies; and integration of new technology. This study will be of interest to scientists studying rural economy, aboriginal economic development, international arts and crafts, cross-cultural clothing, historical clothing, and other related fields.
\end{abstract}

KEY WORDS: Culture - Arctic - Inuit - Aboriginal community economic development - Handicrafts industry $\cdot$ Cross-cultural economic development $\cdot$ Women in development $\cdot$ Northern business

\section{INTRODUCTION}

Industry recognizes the need to understand cultural influences on productivity levels and devotion to producing products (Jamieson 1987, Quigley \& McBride 1987, Robinson \& Ghostkeeper 1987, Department of Economic Development and Tourism 1990, Stabler et al. 1990, Erasmus \& Ensign 1991, Weissling 1991, Wuttunee 1992). Climate also plays a critical role in economic development, especially when studying a specific sector of the economy (Goos 1989). In order to develop effective development strategies in the eastern Arctic, climate and cultural factors need to be examined. The purpose of this paper is to identify climate and cultural factors influencing the Minnguq Sewing Group in Broughton Island, Northwest Territories (N.W.T.), Canada, and to relate this information to relevant literature on economic development.
Unemployment has been a serious problem ever since the traditional economy collapsed in the 1930s and 1940s (Stabler \& Howe 1990). Stabler \& Howe (1990) and Stabler (1989) summarize historical, contemporary, and future unemployment trends for the N.W.T. The birth rate in the N.W.T. is 3 times the national average with over $42 \%$ of the population less than 20 yr old. This rapid increase in population, combined with extreme climate, has strong socio-economic implications (Alan et al. 1993). In 10 yr over 6000 new jobs will be needed in order to maintain even the present low employment rate in the N.W.T. (Department of Economic Development and Tourism 1990, Employment and Immigration Canada 1990). Nationally, 5000 aboriginal people must enter the work force annually for the next $5 \mathrm{yr}$ in order to maintain the current low employment rate for aboriginal people (which is double the non-native rate of low employment) (Jamieson 1987, Department of Economic Development and 
Tourism 1990). Education and specialized training are desperately needed in order to alleviate the high unemployment rate (Department of Economic Development and Tourism 1990, Stabler \& Howe 1990, Stabler et al. 1990). Inuit hold $3 \%$ of the federal public service jobs in the Nunavut (eastern Arctic) region and $45 \%$ of the Government of the Northwest Territory (GNWT) jobs (Inuit Management and Development Task Force 1986). At a time of rapidly growing population and critical levels of unemployment, it is important to understand the factors influencing successful employment ventures.

\section{METHODS}

The Minnguq Sewing Group invited researchers, using participatory action research methods, to help with specific aspects of their business development. Field research was conducted from January to August 1991 in Broughton Island. It was conducted with the assistance of Val Kosmenko, Tamara Tuchak, and members of the Minnguq Sewing Group. Informal interviews with the seamstresses, hunters, and skin preparers were used to collect information on the impact of climate and culture on product line development, decision making processes, and production techniques. Analysis of collected data identified climate and cultural factors inhibiting and supporting economic development.

\section{RESULTS AND DISCUSSION}

A summary of trade and employment activity in the Broughton Island area and specifically at the Minnguq Sewing Group provides an historical context. An analysis of the Minnguq Sewing Centre reveals climate and cultural factors influencing business success.

\section{Broughton Island}

The hamlet of Broughton Island is situated on an island with the same name located of the rugged east coast of Baffin Island in the eastern Canadian Arctic. Inuit from this area saw their first non-native in 1606 when William Baffin's ship was caught in local pack ice. By the early 1600s, European whalers explored the area and established a whaling station at Kivitoo ( $65 \mathrm{~km}$ north of Broughton Island). This contact initiated the first, long-term trading relationship between these 2 groups in the Broughton Island area. In 1956-57, 61 Inuit moved permanently onto Broughton Island when the Distant Early Warning (DEW) line sta- tion was under construction (Kemp 1984, Weissling 1991). Fifteen Inuit were formally employed at this time. By 1957 a few Inuit were selling carvings at the DEW line site (Graburn 1978). At this time Inuit women's contribution to the informal economy was limited by a dramatic drop in hunting activities around the DEW line site (because of increased dependancy on DEW line site supplies) which resulted in the lack of necessary materials. By 1960, Inuit living near the site resumed active hunting and their standard of living improved dramatically (Weissling 1991). Women were able to contribute to their families' quality of life. According to Anders (1966), wage employment earnings rose dramatically with social welfare payments, seal skin sales, construction projects, and fur sales. In 1968, a government-subsidized, territory-wide carving and handicraft cooperative was started by the Department of Indian Affairs and Northern Development. This provided the first source of formal cash income for Inuit women in the Broughton-Pangnirtung area (Weissling 1991). The cooperative now no longer exists.

Today, the population of Broughton Island is 450 (Municipal Records 1991); over 95\% are Inuit. The main economic activities are harvesting marine mammals, waterfowl, caribou, and fish for food, guiding non-natives on hunts, taking tourists on dog sled or fishing trips, and selling handicrafts. A few Inuit work at territorial, municipal, Parks Canada, hotel, and retail jobs. Several main sources of income, including the DEW line site, trapping, sealing, and carving, have either been terminated or the market has crashed (Department of Economic Development and Tourism 1990). There is a definite need for economic development that considers the Arctic climate, available resources, and cultural attributes.

\section{Minnguq Sewing Group}

In the 1960 s, Inuit on Baffin Island started to produce clothing for southern export (Graburn 1978, Inuit Fine Art Task Force 1985). The arts and crafts industry provided a link between the pre-1950s land-based economy (hunting and trapping) and the post-1970s commercial production economy (land claims, government assistance). A community initiated economic development project called the Minnguq (Inuktitut for 'beetle') Sewing Group began in the late 1970s. This group was started by several Inuit women interested in selling seal skin boots (Oakes 1991) (Fig. 1). They began by using skins donated by their families to make footwear. Their business expanded to about 400 boot sales per year by 1990 and a new product line of bags. The number of seamstresses employed by Minnguq varies seasonally 
Fig. 1. Yukipa Audlakiak, Louisa Alookie, and Sarah Kooneeliusie are a few of the women who have contributed to the success of Minnguq

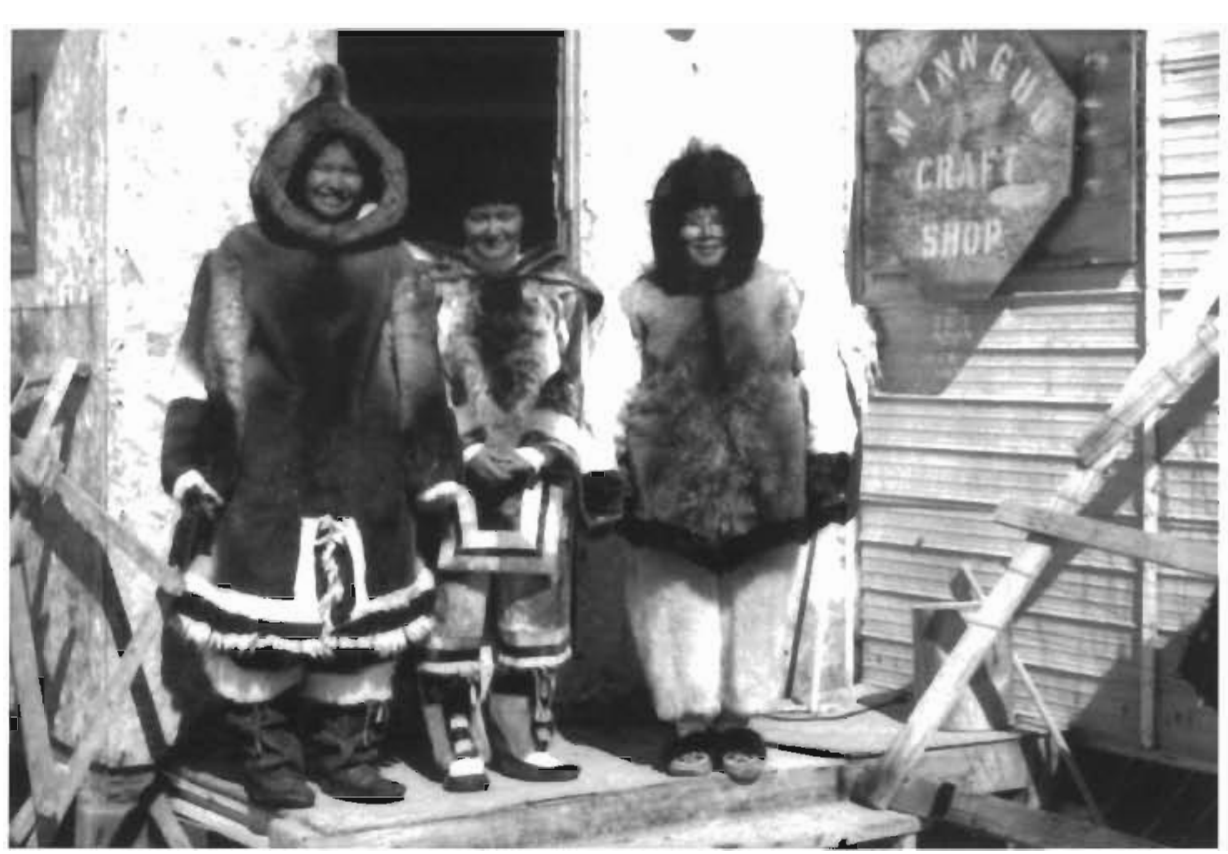

and depends on other community commitments. When requests for products are received, they are announced on the local radio and seamstresses are invited to let Minnguq know if they would like to fill that specific order. Skin boots are the main sales item and sell for approximately $\$ 250$ a pair (depending on size and decoration). The hunters, skin preparers, and sewers are paid by the piece. Consumers are primarily from the Northwest Territories, although individuals from Montreal, Winnipeg, Edmonton, and other southern cities also purchase products from the Minnguq Sewing Group. Seamstresses advertise their products by word of mouth and by a recently published catalogue.

The territorial and federal government introduced the Canadian Economic Development Strategy (CAEDS) in 1989. An economic development officer began helping Minnguq fill in the seemingly endless pages of paper work for government funding proposals. Funds received from successful proposals were used to pay for consultants, training workshops, and equipment including industrial sewing machines. Non-native consultants were used to train interested women in industrialized skin preparation techniques, production techniques using industrial sewing machines, and product line development skills. A local seal skin tannery was funded to complement Minnguq's activities. Governments must continue to play a positive, active role in economic development (Gillis et al. 1987, Stabler \& Howe 1990). It is critical for members of the Minnguq Sewing Group to take into consideration the factors influencing their business, including climate and cultural barriers, as well as the beneficial aspects of these factors. These considera- tions are also important when developing training programs which will help to build the linkage between traditional and contemporary skills needed to successfully run this business.

\section{Climate and cultural influences}

Climate and cultural attributes are closely interconnected in communities living a subsistence lifestyle (Tetsuro 1971). Traditional forms of social organization and the subsistence lifestyle are based on reciprocity and communal responsibilities rather than individual profiteering (Kemp 1984). Income earned by the Minnguq Sewing Group plays a significant role in supporting hunting activities by paying hunters money needed for gas so they can go back out hunting. This in turn reinforces traditional sewing, food preparation, and socialization skills within a contemporary context. In this way the whole community benefits and seamstresses become part of the contemporary sharing system.

Problems occur when unstable weather conditions prevent families from getting out on the land or from returning to town so they are cut off from their contributions to the informal economy. Historically and currently, storms, seasonal changes, and travelling conditions play a key role in the type and amount of natural resources Inuit are able to collect. In Broughton Island, shifts in freeze up, break up, and high winds restrict hunters' ability to hunt seals needed for their skins to produce most craft items. Climate also plays a primary role in shipping and receiving goods. Supplies 
required from southern centres must be flown in on the weekly flights from Iqaluit or sent up on the barge once a year each summer. During unstable weather conditions flights are cancelled, making it impossible to acquire necessary supplies, halting production of product lines dependant on southern materials and increasing the need for large inventories of critical supplies. Flights cancelled due to storms also make it difficult to meet delivery due dates, especially during periods when Broughton Island faces several weeks of stormy weather. This happens regularly in fall and winter. In these situations, perishable food freight is given priority over regular mail.

Local businesses are stronger if they incorporate and build on the strengths offered by the community (Norbert 1987. Keane 1990). It is important for the individuals directly involved in the business and the community in general to develop, implement, and evaluate

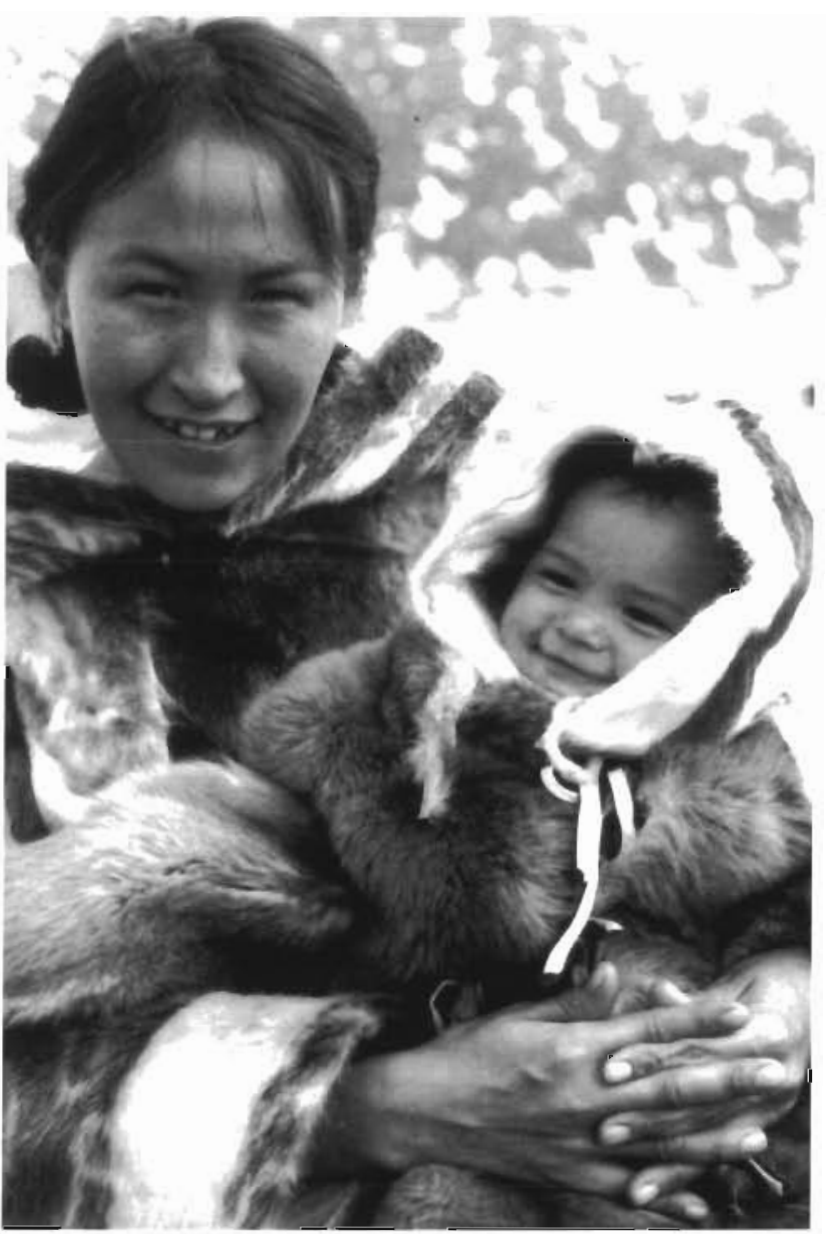

Fig. 2. From the Inuit seamstress' perspective, the success of the Minnguq Sewing Centre is based on the ability of people like Yukipa Qiyutaq to pass on her skills to younger generations. Their goal is to turn cultural barriers into opportunities to develop culturally relevant businesses their business plan. In this way social, economic, and environmental concerns of the community will be integrated into the business plan (Clarke 1981, Ross \& Usher 1986). This was accomplished at the Minnguq Sewing Centre by cooperating with other community members. The municipality provided space, the Hunting and Trapping Association provided freezers, the Housing Corporation allowed Minnguq seamstresses access to their xerox machine and the school provided access to computers. Advisory and training support was provided by the Department of Economic Development and Tourism, University of Alberta, and Sinaaq Enterprises (the Development subsidiary of Inuit Tapirisat of Canada). The end result is a community-based sustainable development project with socially significant returns. Seamstresses used the byproducts of seals, providing hunters with 1 small outlet for seal skin sales. Seamstresses involved with Minnguq are provided training opportunities, opportunities to participate in economic development, new personal skills, and entrepreneurial skills. This business provides seamstresses with the opportunity to pass on traditional skills and new skills as they did in the past (Oakes 1988) (Fig. 2). According to Keane (1990), when community initiatives provide this type of opportunities for personal development, the project or business can be considered successful. Profit is not the only criterion for success.

Traditional skills can be used in innovative ways to create viable modern products and to manage contemporary businesses (Quigley \& McBride 1987, Robinson \& Ghostkeeper 1987, Bhala \& James 1991). The Minnguq Sewing Group blends a combination of homebased manufacturing with workshop-style production as it integrates traditional and contemporary cultural values and seasonal weather conditions. This is a common practise for home-based or workshop-style businesses producing handicrafts and other hand-made items (Grabowski 1989, Park and Anderson 1991, Mayoux 1992). Co-operatives provide an opportunity for women to use their traditional skills in a manner that combines collective activities with income generation. The production process used by Minnguq blends traditional Inuit skills and values with contemporary business needs. Women control when and where they sew items for Minnguq, enabling them to respond to weather conditions and cultural influences. During spring and summer seamstresses prefer to take their family hunting and fishing rather than staying in town to look after the business. In contrast, during stormy winter weather, seamstresses enjoy the opportunity to get together to visit, sew, and make some money. Climate has similar impacts on motivation and economic development in other regions of the world (Lee 1957) Sorne work at home where they can take care of young 
Fig. 3. Atasinak Kilabuk enjoys sewing at home where she can be with her granddaughter

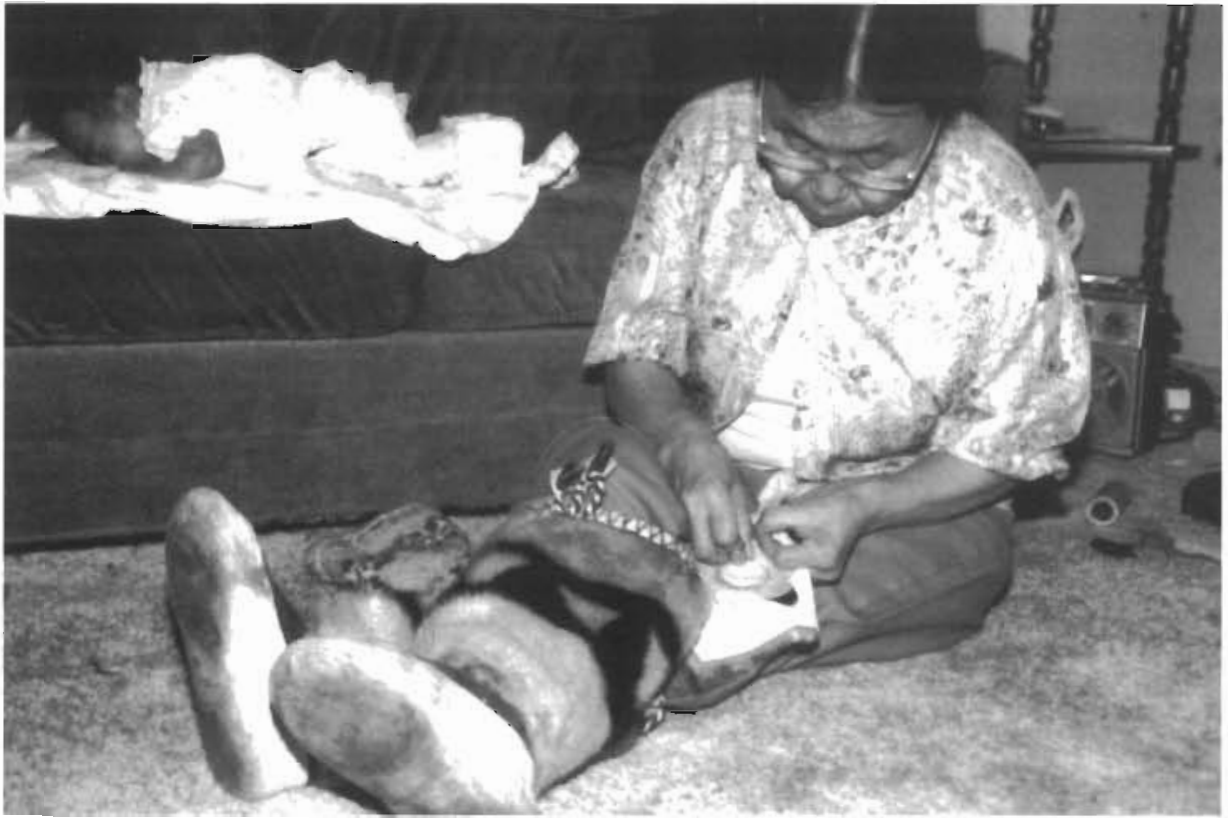

children or the elderly while they are sewing (Fig. 3). Volunteer or paid babysitters are needed to supervise their children if seamstresses want to work at the sewing centre. Others enjoy sewing at Minnguq because they can set their sewing down without worrying about somebody getting into it. Local businesses, such as the Minnguq Sewing Centre, which support traditional value systems have a dramatically greater rate of success than those in conflict with traditional values (Te'o \& Fairbairn 1988).

The cost of labour and amount of labour required to produce an item restricts business success. Hand crafted production is labour intensive; therefore, it is most practical in regions where inexpensive labour is available. Generally, inexpensive labour is scarcer in regions with developed economies than in regions with informal economies; however, the demand for hand crafted products is higher in developed economies (Park \& Anderson 1991). In the Canadian North labour is expensive and hand crafted work is built on generations of knowledge. Although Inuit live in an area where the informal economy flourishes and formal economic development is scarce, they express financial expectations similar to other Canadians. It is unrealistic for them to sew for a low wage. Earning a fair income for their work will help Inuit gain a sense of financial accomplishment and independence. A dilemma facing Minnguq is that seamstresses who sell products directly to the consumer make $100 \%$ of the profit, whereas seamstresses who fill orders for Minnguq make about $50 \%$ of the profit. The money is used by Minnguq to cover overhead costs while seam- stresses selling out of their home do not consider their household overhead when they price an item. Minnguq has blended traditional technology with conventional and emerging technology (Fig. 4). Industrial sewing machines and ancient stitching techniques are combined to maintain quality, decrease labour, and increase production. The use of fax machines has opened up communications between Minnguq, clients, and supply companies. The impact of technological changes on social, political, and economic spheres must also be considered by business (Bhalla \& James 1991). The use of sewing machines was carefully weighed by seamstresses to ensure that they would continue to meet the social and economic needs of the business. Introducing industrialized skin tanning equipment has forced seamstresses to answer questions on waste disposal and maximum seal harvests.

Climate and culture influence the cost and availability of trained labour and the ability to make products efficiently. Adequately trained personnel is difficult to find in small communities, especially during spring and summer (Bone \& Green 1986, Department of Economic Development and Tourism 1990, Stabler \& Howe 1990, Erasmus \& Ensign 1991, Mayoux 1992, M. Phillips pers. comm. 1992, Wuttunee 1992). Trained individuals tend to leave the Minnguq Sewing Group to work at better-paying jobs. For example, one of the initial founders acted as the Director until she accepted a steady job as a cook. Well-trained employees also have the flexibility of resigning from their positions in the spring with the security of knowing they will be the best-trained person for the position in the fall. 


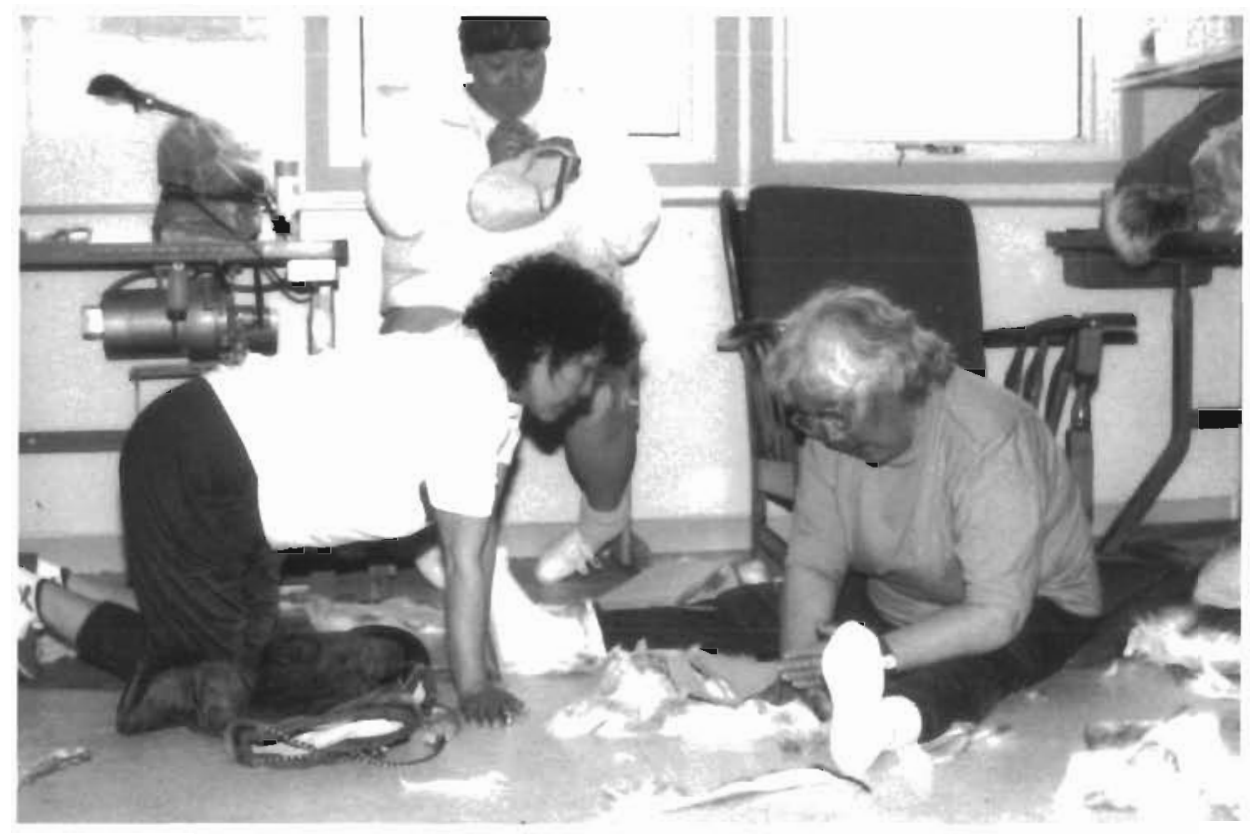

Fig. 4. Sarah Kooneeliusie is a young seamstress who prefers to sew with duffle while more experienced seamstresses (Kilabuk Kooneeliusie) use skin or duffle materials. In order to maintain the skin boot product line some young seamstresses (Louise Alookie) are learning the necessary skills from their elders

The social organization of some societies lends itself to training more entrepreneurs than others (Gillis et al. 1987, Te'o \& Fairbairn 1988). Some social structures financially reward people who strive to continually improve their creative work-related skills while other social structures encourage the development of skills that require less risk taking and less innovative thinking. Traditional Inuit values complement modern business skills in many ways (Kanahele 1987, Robinson \& Ghostkeeper 1987, Grabowski 1991). Successful aboriginal hunters need a variety of characteristics including: the ability 'to plan, take risks, tolerate uncertainty, be flexible, and work hard' (Kanahele 1987, p. 5). The founding members of the Minnguq Sewing Group also share these key characteristics. For generations seamstresses were responsible for planning when skins were prepared and deciding what types of garments were needed to meet the needs of each season. Clothing was designed to help families adapt to weather, snow, and ice conditions. Contemporary women continue to plan household clothing and food production. They also are experienced at planning municipal events and managing hamlet activities. Throughout these activities they take risks, tolerate uncertainty, and demonstrate their flexibility. They explore new materials and quickly adapt them to meet contemporary clothing needs in the community and out on the land. Cultural attributes which support sound economic development can also be the factors which become barriers to successful business. For example, Inuit use creative problem solving methods which are critical for innovative products; however, consumers may be disappointed with some substitutions resulting from the lack of certain supplies. Other cultural differences facing women at Minnguq are their unorthodox book keeping and management procedures. The same issues restricted the economic growth of artists in Pangnirtung (G. Rymer pers. comm. 1992) and other northern communities (Wuttunee 1992).

\section{CONCLUSIONS}

The success of the Minnguq Sewing Group is influenced by climate and cultural factors. Climate and culture regulate the availability of natural and human resources, as well as the ability to build a contemporary business by adapting traditional skills. Business managers need to understand the impact climate and culture have on collecting resources, individual productivity, and product distribution. Climate and culture played a key role in restricting the types of resources and the availability of these resources. Climate and culture also influenced production and distribution deadlines. These factors can be considered attributes needed for the successful development of crafts produced by aboriginal people in isolated rural communities. Successful businesses need to consider efficient production methods, adopt appropriate modern technology, understand the demands of the marketplace, maintain quality control, and maintain financial control.

For generations Inuit have excelled at planning their own direction. They take risks after carefully weighing the cost to the community. Limited access to resources has enabled them to exercise creative and innovative 
decision making processes. These traits are compatible with values needed to run a successful business. In addition, a strong sense of community and community loyalties can be a benefit or detriment to Inuit business initiatives.

Additional research is needed to identify the impact that change in climate would have on the eastern Arctic Inuit handicraft industry. Comparisons with handicraft industries in other regions would also be useful for business consultants. The relationship between climate, culture, and economic development needs to be explored further by studying the relationship between climate and other specific industries such as tourism and sport hunting within a cultural context.

Acknowledgements. The Minnguq Sewing Group. Shane Parrish, and Broughton Island Hamlet Council are thanked for their assistance during the planning and implementing stages of the project. The following individuals are specially mentioned for the support they provided: Nellie Allan, Mary and Louisa Alookie, Leah and Yukipa Audlakiak, Anna Joannasie, Annie Kakukdluk, Minah Keeyoutak, Kilabuk Kooneeliusie, Sarah and Allan Kooneeliusie, Aunt Sarah Kooneeliusie, Samonie Kooneeliusie, Martha Kopali, Susan Kownirk, Imona Natsiakpik, Leah Newkingnak, Martha Nookiguaq, and Ooleepeka and her family are sincerely thanked for their assistance with this project. Val Kosmenko and Tamara Tuchak are thanked for their research assistance with the Minnguq Sewing Centre from January to March and June to August 1991 respectively. Their dedication and creativity during the product design phase was invaluable. Dr Rick Riewe is thanked for his support throughout the planning and writing phases of this project. The Department of Economic Development and the Department of Indian and Northern Affairs are sincerely thanked for their financial contribution.

\section{LITERATURE CITED}

Alan A, Blommestein E, Broader J (1993) Climate change and socio-economic impacts. In: Maul G (ed) Climate change in the Intra-American Sea. Edward Arnold Publishers, New York, p 333-349

Anders G (ed) (1966) Baffin Island - East Coast: an area economic survey. Industrial Division, Northern Administration Branch, Department of Indian Affairs and Northern Development, Ottawa

Bhalla A, James D (1991) Integrating new technologies with traditional economic activities in developing countries: an evaluative look at 'technology blending'. J Develop Areas 25 (July):477-496

Bone R, Green M (1986) Accessibility and development of Metis communities in Northern Saskatchewan. Can Geogr 30(1):66-71

Clarke R (1981) Our own resources, co-operatives and community economic development in rural Canada. The Arkleton Trust, Langholm, UK

Department of Economic Development and Tourism (1990) Economy in transition: an agenda for action. Government of the Northwest Territories, Yellowknife

Employment and Immigration Canada (1990) Pathways to success: aboriginal employment and training strategy.
LM111/11/90. Minister of Supply and Services Canada, Ottawa

Erasmus P, Ensign G (1991) A practical framework for community liaison work in Native communities. Justin Publishers, Brandon, $\mathrm{MB}$

Gillıs M, Perkins D, Roemer M, Snodgrass D (1987) Economic development, 2nd edn. Norton \& Co. New York

Goos $T$ (1989) The effect of climate and climate change on the economy of A.lberta. Climate Change Digest no 89-05. Environment Canada, Ottawa

Grabowski R (1989) Development as displacement: a critique and alternative. J Develop Areas 23(4):505-518

Grabowski R (1991) Economic development and the traditional sector: a comparison of Japanese and African experience. Develop Econ 29(1): 3-18

Graburn N (1978) Commercial Inuit art: a vehicle for the economic development of the Eskimos of Canada. Inter-Nord 15 (December): 131-142

Inuit Fine Art Task Force (1985) Report to Tagak Curley, Minster of Economic Development and Tourism. October 1985. Government of the Northwest Territories, Yellowknife

Inuit Management and Development Task Force (1986) A strategy for Inuit management development. April, 1986. Government of the Northwest Territories, Yellowknife

Jamieson M (1987) Aboriginal women - barriers to economic development. Pauktuutit, Ottawa

Kanahele G (1987) Creating wealth by blending traditional values and modern business skills. In: Otto L (ed) Seizing the day: local control and rural economic development. A report on the Yukon-Kuskokwim Conference, April 24-25, 1987. Kuskokwim Community College, Bethel, AK, p $3-5$

Keane M (1990) Economic development capacity amongst small rural communities. J rural Stud 6(3):291-301

Kemp W (1984) Baffinland Eskimo. In: Damas D (ed) Handbook of North American Indians 5 (Arctic). Smithsonian Institution Press, Washington, DC, p 463-475

Lee D (1957) Climate and economic development in the tropics. Harper Brothers, New York

Mayoux L (1992) From idealism to realism: women, feminism, and empowerment in Nicaraguan tailoring co-operatives. Develop Change 23(2):91-114

Municipal Records (1991) 1991 population. Hamlet of Broughton Island, NWT

Norbert E (1987) Increasing profits by cooperative marketing of handicrafts. In: Otto L (ed) Seizing the day: local control and rural economic development. A report on the YukonKuskokwim Conference, April 24-25, 1987. Kuskokwim Community College, Bethel, AK, p. 15-16

Oakes J (1988) Cultural education: from the igloo to the classroom. Can J Native Stud 15(2):4 1-48

Oakes J (1991) History of Minnguq sewing centre. Report submitted to the Royal Wax Museum, Victoria, BC

Park Y, Anderson K (1991) The rise and demise of textiles and clothing in economic development: the case of Japan. Econ Develop cult Change 39(3):531-548

Quigley N, McBride N (1987) The structure of an Arctic microeconomy: the traditional sector in community economic development. Arctic 40(3):204-210

Robinson M, Ghostkeeper E (1987) Native and local economics: a consideration of economic evolution and the next economy. Arctic 40(2):138-144

Ross D, Usher P (1986) From the roots up; economic development as if community mattered. The Bootstrap Press, Croton-on-Hudson, NY

Stabler J (1989) Dualism and development in the Northwest 
Territories. Econ Develop cult Change 37(4):805-839

Stabler J, Howe E (1990) Native participation in northern development: the impending crisis in the NWT Can Public Policy 16(3):262-283

Stabler J, Tolley G. Howe E (1990) Fur trappers in the Northwest Territories: an econometric analysis of the factors influencing participation. Arctic 43(1):1-8

Te'o I, Fairbairn J (eds) (1988) Island entrepreneurs: problems and performances in the Pacific. Pacific Island Development Center, East-West Center, Honolulu, HI
Tetsuro W (1971) Climate and culture: a philosophical study. Translated by G. Bownas. The Hokuseido Press, Hokusei Weissling L (1991) Inuit redistribution and development: processes of change in the Eastern Canadian Arctic, 1.922-1968. Doctoral thesis, Department of Geography, University of Alberta, Edmonton

Wuttunee W (1992) In business for ourselves. McGill-Queen's Native and Northern Series 8. McGill-Queen's University Press, Arctic Institute of North America, and Faculty of Management of the University of Calgary 